Int. J. Dev. Biol. 58: 343-347 (2014)

doi: $10.1387 / \mathrm{ijdb} .140058 \mathrm{rj}$

\title{
Gene expression suggests double-segmental and single-segmental patterning mechanisms during posterior segment addition in the beetle Tribolium castaneum
}

\author{
RALF JANSSEN* \\ Uppsala University, Department of Earth Sciences, Palaeobiology, Uppsala, Sweden
}

\begin{abstract}
In the model arthropod Drosophila, all segments are patterned simultaneously in the blastoderm. In most other arthropods, however, posterior segments are added sequentially from a posterior segment addition zone. Posterior addition of single segments likely represents the ancestral mode of arthropod segmentation, although in Drosophila, segments are patterned in pairs by the pair-rule genes. It has been shown that in the new model insect, the beetle Tribolium, a segmentation clock operates that apparently patterns all segments in pairs as well. Here, I report on the expression of the segment polarity gene H15/midline in Tribolium. In the anterior embryo, segmental stripes of $\boldsymbol{H} 15$ appear in pairs, but in the posterior of the embryo stripes appear in a single-segmental periodicity. This implies that either two completely different segmentationmechanisms may act in the germ band of Tribolium, that the segmentation clock changes its periodicity during development, or that the speed in which posterior segments are patterned changes. In any case, the data suggest the presence of another (or modified), yet undiscovered, mechanism of posterior segment addition in one of the best-understood arthropod models. The finding of a hitherto unrecognized segmentation mechanism in Tribolium may have major implications for the understanding of the origin of segmentation mechanisms, including the origin of pair rule patterning. It also calls for (re)-investigation of posterior segment addition in Tribolium and other previously studied arthropod models.
\end{abstract}

KEY WORDS: segmentation, arthropod development, arthropod evolution, segment polarity

Our understanding of arthropod segmentation comes primarily from studies on the model organism Drosophila melanogaster. Here, a hierarchic segmentation gene cascade operates to subdivide, in a stepwise fashion, a syncytial blastoderm that later develops without posterior segment addition into the complete adult body. Notably, one step of this segmentation mechanism comprises the temporal establishment of double-segmental units, as shown by the function (and expression) of the pair-rule genes. In most other arthropods, only anterior segments are formed from the blastoderm, and posterior segments are added from a posterior segment addition zone (Davis and Patel 2002). Posterior segment addition with a single-segmental periodicity likely represents the ancestral mechanism, as suggested by morphological observations and gene expression analysis (Schoppmeier and Damen 2005, Janssen 2011). Evidence for double-segmental patterning mechanisms in the blastoderm, superficially comparable to Drosophila pair-rule patterning, has, however, been found in distantly related arthropods (Dearden et al., 2002, Janssen et al., 2012).
Double-segmental patterning has also been found in tissue that is generated from the posterior segment addition zone in the beetle Tribolium castaneum (Choe et al., 2006) in addition to other insects (Davis et al., 2001, Mito et al., 2007, Erezyilmaz et al., 2009) and a distantly related arthropod, the centipede Strigamia maritima (Chipman et al., 2004). These findings support the idea that a double-segmental posterior patterning system may be a conserved component of arthropod (or at least mandibulate) segmentation. On the other hand, a vertebrate-like posterior segment addition mechanism was proposed for arthropods in which an oscillating clock mechanism would underlie posterior segment addition and patterning (Stollewerk et al., 2003, Chesebro et al., 2013). In vertebrates, posterior segments are strictly added and patterned as single segments (somites) (Gomez et al., 2008). Recent studies have revealed the presence of an oscillating vertebrate-like pat-

Abbreviations used in thispaper: $\mathrm{HH}$, hedgehog; $\mathrm{SPG}$, segment polarity gene; wg, wingless.

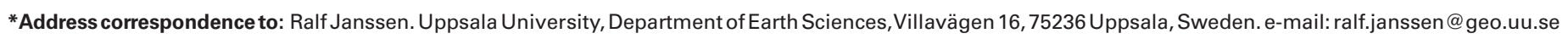




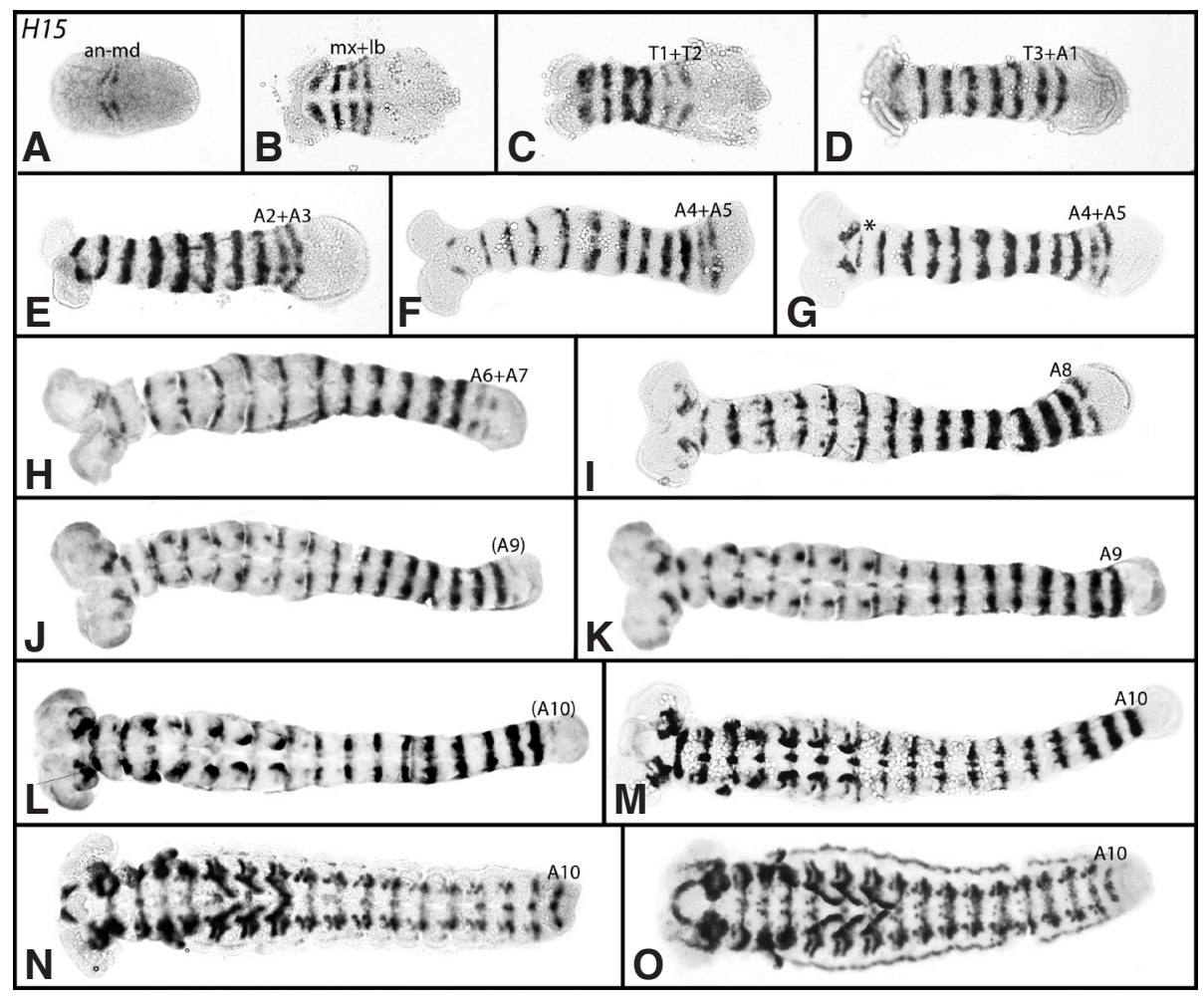

Fig. 1. Expression of H15: appearance of segmental stripes in pairs of two and as single stripes. In all panels anterior is to the left. All embryos, except the embryo shown in (A), have been flat-mounted. (A) Two stripes of expression. (B) Four stripes of expression. (C) Six stripes of expression. (D) Eight stripes of expression. (E) 10 stripes of expression. (F) 12 Stripes of expression. (G) The intercalary stripe (asterisk) forms; 13 stripes of expression. (H) 15 stripes of expression. (I) 16 (!) stripes of expression. (J) 17th stripe of expression appears. (B) 17 stripes of expression. (L) $18^{\text {th }}$ stripe of expression appears. (M) 18 stripes of expression. (N) 18 stripes of expression. (0) 18 stripes. Abbreviations: an, antennal segment; $m d$, mandibular segment, $m x$, maxillary segment; Ib, labial segment; T1-T3, first to third thoracic segment; A1-A11, first to eleventh abdominal segment. Segment abbreviations in brackets indicate nascent expression.

terning mechanism in Tribolium, and at the same time show that this mechanism acts in a two-segment periodicity (Sarrazin et al., 2013, El-Sherif et al., 2013).

I analyzed the expression pattern of the segment-polarity gene H15 (aka midline) in Tribolium and found that this gene is likely regulated in a double-segmental pattern in the blastoderm and most of the posterior segments. However, in the later-developed segments, H15 is apparently regulated in a single-segmental fashion. Thus, my data reveal the presence of a single-segmental patterning system in Tribolium, different from the previously described double-segmental mechanism. This single mechanism, which is likely ancestral, may then have evolved into the double-segmental patterning present in the anterior germ band of Tribolium. Most importantly, however, the new data suggest that an additional mechanism of posterior segment addition may have escaped scrutiny in previous studies in this emerging model organism.

\section{Results}

\section{Expression of Tribolium $\mathrm{H} 15$}

Expression first appears in the form of two segmental stripes that are associated with the primordia of the antennal and the mandibular segments (Fig. 1A). Note that the rudimentary intercalary segment will subsequently form between those stripes and express $\mathrm{H} 15$ at a later developmental stage. Individuals with a single stripe of expression were never found. At the subsequent stage, two additional stripes of expression appear (associated with the maxillary and labial segments) (Fig. 1B). Embryos with three stripes were never found. At the next stage, six stripes are present, of which the posterior most two bands (in the first two thoracic segments) are of the same weakened intensity (compared to the more anterior stripes) (Fig. 1C). Embryos with five stripes were never observed. This periodicity of two additional stripes (and no intermediates) is repeated in three further events, resulting in embryos with eight, 10 , or 12 stripes (Fig. $1 \mathrm{D}-\mathrm{F})$. The next change in the expression pattern concerns the delayed appearance of the intercalary stripe between the antennal and the mandibular stripe (Fig. 1G). In the next stage, embryos with two additional posterior stripes (sixth and seventh abdominal segment) can be found (Fig. 1H). Notably, the pattern of posterior stripe-addition now changes towards a single-segmental mode, in which abdominal stripes eight, nine and ten form (Fig. $1 \mathrm{I}-\mathrm{N}$ ).

At later developmental stages $\mathrm{H} 15$ is expressed along the ventral surface of the limbs (Fig. $1 \mathrm{~K}-\mathrm{O}$ ), the developing heart,

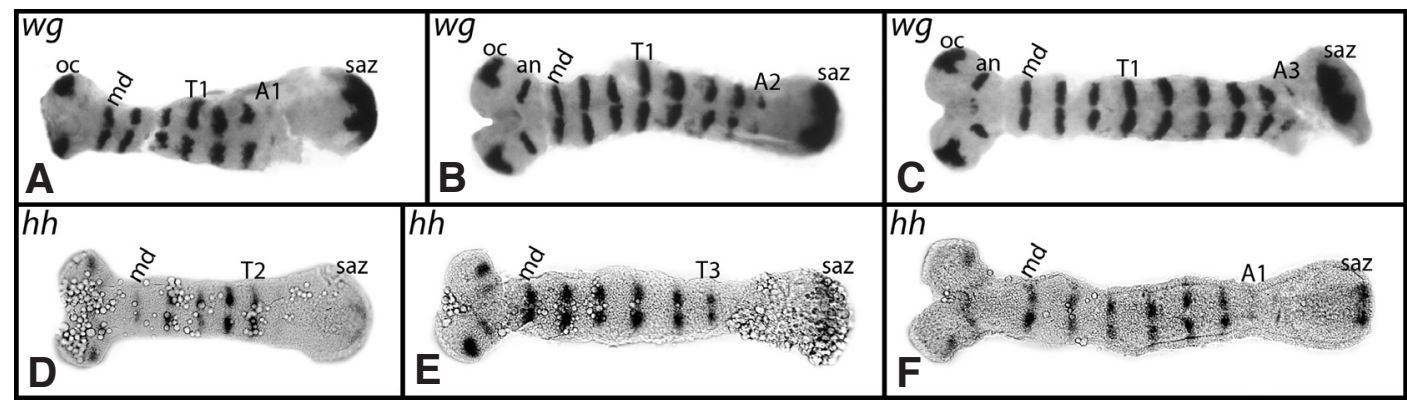

Fig. 2. Expression of wingless (wg) and hedgehog (hh): segmental stripes appear one by one. (A-C) Expression of wg. (DF) Expression of hh. In all panels anterioris to the left. Embryos have been flat-mounted. (A) Stripe of wg in the first abdominal segment forms. (B) Stripe in the second abdominal segment forms. (C) Stripe in the third abdominal segment forms. (D) Stripe of hh in the second thoracic segment forms. (E) Stripe in the third thoracic segment has appeared. (F) Stripe in the first abdominal segment forms. Abbreviations as in Fig. 1, oc, ocular region; saz, segment addition zone. 


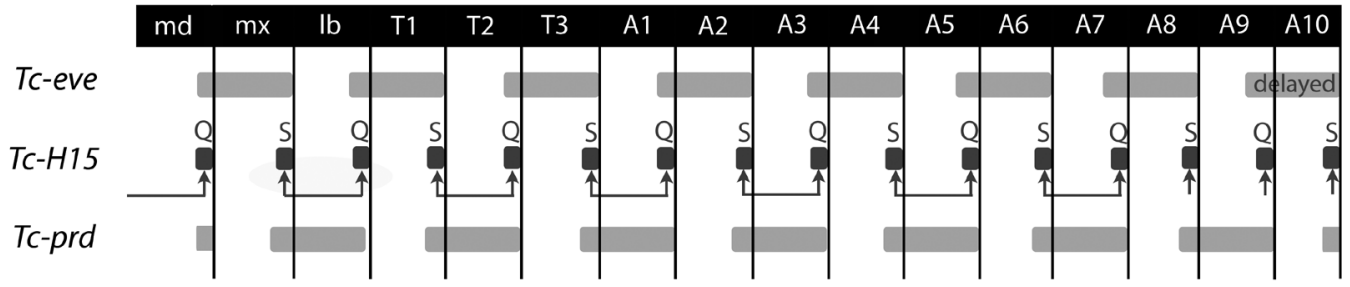

Fig. 3 Summary of $H 15$ expression and its theoretical activation by the pair rule genes even-skipped (eve) and paired (prd). Light grey bars indicate double-segmental primary expression patterns of eve and prd respectively. Note that the last wave ofeve is delayed. " $Q$ " and " $S$ " indicate potential quick and slow activation of $\mathrm{H} 15$ by eve. Dark grey bars indicate single segmental expression of $\mathrm{H} 15$. Stripes of $\mathrm{H} 15$ that appear simultaneously are connected by double-arrows. Stripes of H15 that appear one by one are indicated by simple arrows. Abbreviations: A1-A10, first to tenth abdominal segment; md, mandibular segment; $m x$, maxillary segment; Ib, labial segment; T1-T3, first to third thoracic segment.

dorsally in the labrum, and in the developing ventral nervous system (Fig. $1 \mathrm{~N}, \mathrm{O})$.

\section{Discussion}

\section{Unique regulation of $\mathrm{H15}$ in Tribolium}

In Drosophila, $\mathrm{H} 15$ acts as a segment-polarity gene (SPG) and its function is required to break symmetry of the otherwise bi-directional Hedgehog $(\mathrm{Hh})$ signaling (Buescher et al., 2004). Since the overall expression pattern of $H 15$ is conserved in all hitherto studied arthropods (Prpic et al., 2003, Buescher et al., 2004, Janssen et al., 2008a, b, Svendsen et al., 2009), and since the SPG-network itself is also highly conserved in arthropods including Tribolium (Farzana and Brown 2008, Janssen et al., 2004, 2008a), this implies also that the function of $\mathrm{H} 15$ in the beetle is likely conserved. Notably, however, H15appears to be the only SPG that is regulated in a double-segmental fashion. Other SPGs such as wingless (wg) (Nagy and Carroll 1994) (Fig. 2 A-C), engrailed (en) (Brown et al.,1994) and hedgehog (hh) (Farzana and Brown 2008) (Fig. 2 D-F) appear to be regulated in a single-segmental fashion. It has been shown, however, that the genetic interaction that leads to the activation of $\mathrm{wg}$ in odd and even numbered parasegments (i.e. in adjacent segments) differs considerably (Choe and Brown 2009). It may then be the case that the single-segmental (and strictly anterior to posterior) appearance of $w g$ is merely the result of differences in the upstream regulatory network. This could lead to a temporal delay of $w g$ expression in the posterior of two simultaneously established segmental units.

\section{What is the cause of the double vs. single-segmental appear- ance of $\mathrm{H15}$ ?}

It is obvious that the regulation of $\mathrm{H} 15$ in the posterior abdomen in Tribolium is different when compared to the patterning of the more anterior segments. It is either the case that: two generally different patterning mechanisms function in Tribolium (like in the myriapod Strigamia (discussed in the following section) (Brena and Akam 2013)); or that the apparent regulation of $\mathrm{H} 15$ in pairs is just the result of upstream clock dynamics. This could be the case if the anterior stripe of $\mathrm{H} 15$ that is regulated by a dynamic wave of pair-rule gene expression comes up quickly, while the posterior stripe regulated by the previous wave of pair-rule gene expression comes up slowly. In that way both stripes may appear at the same time. This would be in line with the shifted appearance of $H 15$ in adjacent segments compared to the waves of even-skipped (eve) expression (Choe and Brown 2007) and the fact that the last wave of eve-expression is delayed (El-Sherif et al., 2012). Slowing down of the first 'tick' of the clock towards the end of embryogenesis would then lead to the appearance of single stripes of $\mathrm{H} 15$ in the last formed segments (summarized in Fig. 3). An alternative scenario with paired ( $p r d$ ) being in control of $H 15$ would not require slow and quick activation of $H 15$ in adjacent segments because the doublesegmental domains of prd are in register with the appearance of H15. It would, however, not explain the delayed appearance of $\mathrm{H} 15$ in A8 and A9 without further modification of H15-regulation.

A drastic alternative is that the segmentation-clock may change its periodicity from double-towards single-segmental in nature. If this is the case, then the question is what causes this switch? This may be a matter of available space. Firstly, it is known that the vertebrate segmentation clock "ticks" for as long as presomitic mesoderm is present (the amount of this tissue is consumed during the process of segment addition) (Gomez et al., 2008). It is therefore not unlikely that the arthropod segmentation clock requires comparable tissue (the segment addition zone), independent of whether vertebrate and arthropod segmentation clocks are homologous or analogous. Secondly, we find that in the centipede Strigamia (Geophilomorpha) a double-segmental patterning mechanism exists (likely clockbased as suggested by dynamic gene expression patterns in the saz) (Chipman et al., 2004, Brena and Akam 2013). In this species the saz is expansive. In other myriapods such as the centipede Lithobius forficatus (Lithobiomorpha) the saz is much reduced and no evidence of a double-segmental patterning mechanism has been found. Although it is not unlikely that the double-segmental mechanism in Strigamia is the result of convergent evolution, the large saz may have provided the morphological prerequisite for the evolution of this patterning mechanism. For Tribolium, this could mean that the switch from double- to single-segmental patterning is caused by the shrinking of the saz towards the end of ontogenesis. In order to test this hypothesis it would be interesting to study gene expression of $H 15$ (and other SPGs) in arthropod species with small, intermediate and large segment addition zones.

\section{On the origin of pair rule-like patterning mechanisms}

The current study revealed the possible involvement of a single and a double-segmental patterning system in Tribolium. This is strikingly similar to what a very recent study has demonstrated to be the case for the centipede Strigamia (Brena and Akam 2013). However, in Strigamia the change from double- to single-segmental patterning apparently comes with a general change of genetic regulation, and is not the result of a slower-ticking clock mechanism (Brena and Akam 2013). With our current knowledge we cannot decide whether the similarities found in Triboliumand Strigamia are the result of convergent evolution or, alternatively, the evolutionary remnant of an ancestral mandibulate patterning system that involved single- and double-segmental patterning mechanisms. 
This is because the unique patterning of the posterior-most abdominal segments has not been recognized until now, except for the statement of El-Sherif et al., (2012) that the appearance of the last stripe of even-skipped expression is significantly delayed.

\section{Future perspectives}

As a consequence of the current study, it will now be necessary to further investigate posterior (single) segment addition in Tribolium in order to find out if it underlies different regulatory mechanisms than double-segmental patterning, and if those are potentially similar to the mechanisms of single segment addition in Strigamia. We also will have to investigate posterior segment addition in other insects that pattern segments in pairs. The question is whether they pattern all segments by the same double-segmental mechanism, and if this is not the case, if single segmental posterior segment patterning underlies the same (or similar) genetic regulation system as in Strigamia and/or Tribolium. A first step must be to study the expression of known posterior segmentation genes, such as the pair-rule genes, in relation to the expression of $\mathrm{H} 15$, and to study functional aspects of $\mathrm{H} 15$ during anterior and posterior segmentation in Tribolium. The aim of this paper is to demonstrate that differences in anterior and posterior segmentation exist in the model arthropod Tribolium, and to highlight the urgent need for further detailed investigation of Tribolium segmentation mechanism(s). If both, single and double-segmental patterning mechanisms were present in the last common ancestor of arthropods (or at least mandibulates), this would explain the widespread appearance of pair rule-like expression patterns throughout Arthropoda.

\section{Materials and Methods}

Gene cloning and expression of Tribolium H15 in the developing heart has been described before (Janssen and Damen 2008). Fragments of wingless $(w g)$ and hedgehog $(h h)$ were amplified with the degenerate primers described by Damen (2002) and Janssen et al., (2004). Expression of wg was described by Nagy and Carroll (1994) and expression of $h h$ has been described by Farzana and Brown (2008). In-situ hybridization of embryos was performed as described by Tautz and Pfeifle (1989). Flat-mounted embryos were analyzed under a Leica MZFLIII dissection microscope equipped with a Leica DFC490 digital camera, or under a Nikon ECLIPSE E400 microscope equipped with a Nikon D70 portable digital camera. Brightness, contrast and color values were adjusted in all images using the image processing software Adobe Photoshop CS2 (Version 9.0.1 for Apple Macintosh).

\section{Acknowledgements}

I would like to thank native English speakers Aodhán D. Butler, Illiam Jackson and Stephen Poropat for proofreading of the final version of the manuscript.

\section{References}

BRENA, C., AKAM, M. (2013) An analysis of segmentation dynamics throughout embryogenesis in the centipede Strigamia maritima. BMC Biol 11: 112.

BROWN, S. J., PATEL, N. H., DENELL, R. E. (1994) Embryonic expression of the single Tribolium engrailed homolog. Dev Genet 15: 7-18.

BUESCHER, M., SVENDSEN, P. C., TIO, M., MISKOLCZI-McCALLUM, C., TEAR, G., BROOK, W. J., CHIA, W. (2004) Drosophila T box proteins break the symmetry of hedgehog-dependent activation of wingless. Curr Biol 14: 1694-1702.

CHESEBRO, J. E., PUEYO, J. I., COUSO, J. P. (2013) Interplay between a Wntdependent organizer and the Notch segmentation clock regulates posterior development in Periplaneta americana. Biol Open 2: 227-237.
CHIPMAN, A. D., ARTHUR, W., AKAM, M. (2004) A double segment periodicity underlies segment generation in centipede development. Curr Biol 14: 1250-1255.

CHOE, C. P., MILLER, S. C., BROWN, S. J. (2006) A pair-rule gene circuit defines segments sequentially in the short-germ insect Tribolium castaneum. Proc Natl Acad Sci USA 103: 6560-6564.

CHOE, C. P., BROWN, S. J. (2007) Evolutionary flexibility of pair-rule patterning revealed by functional analysis of secondary pair-rule genes, paired and sloppypaired in the short-germ insect, Tribolium castaneum. Dev Biol 302: 281-294.

CHOE, C. P., BROWN, S. J. (2009) Genetic regulation of engrailed and wingless in Tribolium segmentation and the evolution of pair-rule segmentation. Dev Biol 325: 482-491.

DAMEN, W. G. (2002) Parasegmental organization of the spider embryo implies that the parasegment is an evolutionary conserved entity in arthropod embryogenesis. Development 129: 1239-1250.

DAVIS, G. K., JARAMILLO, C. A., PATEL, N. H. (2001) Pax group III genes and the evolution of insect pair-rule patterning. Development 2001 128: 3445-3458.

DAVIS, G. K., PATEL, N. H. (2002) Short, long, and beyond: molecular and embryological approaches to insect segmentation. Annu Rev Entomol 47: 669-699.

DEARDEN, P. K., DONLY, C., GRBIC, M. (2002) Expression of pair-rule gene homologues in a chelicerate: early patterning of the two-spotted spider mite Tetranychus urticae. Development 129: 5461-5472.

EL-SHERIF, E., AVEROF, M., BROWN, S. J. (2012) A segmentation clock operating in blastoderm and germband stages of Tribolium development. Development 139: 4341-4346.

EREZYILMAZ, D. F., KELSTRUP, H. C., RIDDIFORD, L. M. (2009) The nuclear receptor $E 75 A$ has a novel pair-rule-like function in patterning the milkweed bug, Oncopeltus fasciatus. Dev Biol 334: 300-310.

FARZANA, L., BROWN, S. J. (2008) Hedgehog signaling pathway function conserved in Tribolium segmentation. Dev Genes Evol 218: 181-192.

GOMEZ, C., OZBUDAK, E. M., WUNDERLICH, J., BAUMANN, D., LEWIS, J., POURQUIE, O. (2008) Control of segment number in vertebrate embryos. Nature 454: 335-339.

JANSSEN, R., PRPIC, N. M., DAMEN, W. G. (2004) Gene expression suggests decoupled dorsal and ventral segmentation in the millipede Glomeris marginata (Myriapoda: Diplopoda). Dev Biol 268: 89-104.

JANSSEN, R., DAMEN, W. G. (2008) Diverged and conserved aspects of heart formation in a spider. Evol Dev 10: 155-165.

JANSSEN, R., BUDD, G. E., DAMEN, W. G., PRPIC, N. M. (2008a) Evidence for Wg-independent tergite boundary formation in the millipede Glomeris marginata. Dev Genes Evol 218: 361-370.

JANSSEN, R., FEITOSA, N. M., DAMEN, W. G., PRPIC, N. M. (2008b) The T-box genes $\mathrm{H} 15$ and optomotor-blind in the spiders Cupiennius salei, Tegenaria atrica and Achaearanea tepidariorum and the dorsoventral axis of arthropod appendages. Evol Dev 10: 143-154.

JANSSEN, R. (2011) Diplosegmentation in the pill millipede Glomeris marginata is the result of dorsal fusion. Evol Dev 13: 477-487.

JANSSEN, R., DAMEN, W. G., BUDD, G. E. (2012) Expression of pair rule gene orthologs in the blastoderm of a myriapod: evidence for pair rule-like mechanisms? BMC Dev Biol 12:15.

MITO, T., KOBAYASHI, C., SARAHINA, I., ZHANG, H., SHINAHARA, W., MIYAWAKI, K., SHINMYO, Y., OHUCHI, H., NOJI, S. (2007) even-skipped has gap-like, pairrule-like, and segmental functions in the cricket Gryllus bimaculatus, a basal, intermediate germ insect (Orthoptera). Dev Biol 303: 202-213.

NAGY, L.M., CARROLL, S. (1994) Conservation of wingless patterning functions in the short-germ embryos of Tribolium castaneum. Nature 367: 460-463.

PRPIC, N. M., JANSSEN, R., WIGAND, B., KLINGLER, M., DAMEN, W. G. (2003) Gene expression in spider appendages reveals reversal of exd/hth spatial specificity, altered leg gap gene dynamics, and suggests divergent distal morphogen signaling. Dev Biol 264: 119-140.

SARRAZIN, A. F., PEEL, A.D., AVEROF, M. (2012) A segmentation clock with twosegment periodicity in insects. Science 336: 338-341.

SCHOPPMEIER, M., DAMEN, W. G. (2005) Expression of Pax group III genes suggests a single-segmental periodicity for opisthosomal segment patterning in the spider Cupiennius salei. Evol Dev 7: 160-169.

STOLLEWERK, A., SCHOPPMEIER, M., DAMEN, W. G. (2003) Involvement of Notch 
and Delta genes in spider segmentation. Nature 423: 863-865.

SVENDSEN, P. C., FORMAZ-PRESTON, A., LEAL, S. M., BROOK, W. J. (2009) The Tbx20 homologs midline and H15 specify ventral fate in the Drosophila melanogaster leg. Development 136: 2689-2693.
TAUTZ, D., PFEIFLE, C. (1989) A non-radioactive in situ hybridization method for the localization of specific RNAs in Drosophila embryos reveals translational control of the segmentation gene hunchback. Chromosoma 98: 81-85. 


\section{Further Related Reading, published previously in the Int. J. Dev. Biol.}

Genetic control of morphogenesis - Hox induced organogenesis of the posterior spiracles James Castelli-Gair Hombría, María Luisa Rivas and Sol Sotillos

Int. J. Dev. Biol. (2009) 53: 1349-1358

http://dx.doi.org/10.1387/ijdb.072421jc

Head-tail patterning of the vertebrate embryo: one, two or many unresolved problems? Claudio D. Stern, Jeroen Charité, Jacqueline Deschamps, Denis Duboule, Anthony J. Durston, Marie Kmita, Jean-François Nicolas, Isabel Palmeirim, Jim C. Smith and Lewis Wolpert Int. J. Dev. Biol. (2006) 50: 3-15

http://dx.doi.org/10.1387/ijdb.052095cs

Transcriptional regulation and the evolution of development

Gregory A Wray

Int. J. Dev. Biol. (2003) 47: 675-684

http://www.intjdevbiol.com/web/paper/14756343

Segmentation: mono- or polyphyletic?

Elaine C Seaver

Int. J. Dev. Biol. (2003) 47: 583-595

http://www.intjdevbiol.com/web/paper/14756334

Cell lineage analysis of pattern formation in the Tubifex embryo. I. Segmentation in the mesoderm

A Goto, K Kitamura and T Shimizu

Int. J. Dev. Biol. (1999) 43: 317-327

http://www.intjdevbiol.com/web/paper/10470648

5 yr ISI Impact Factor $(2011)=2.959$

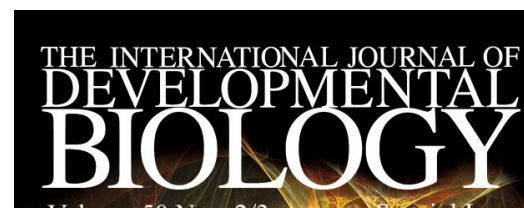

Volume 50 Nos. $2 / 3$

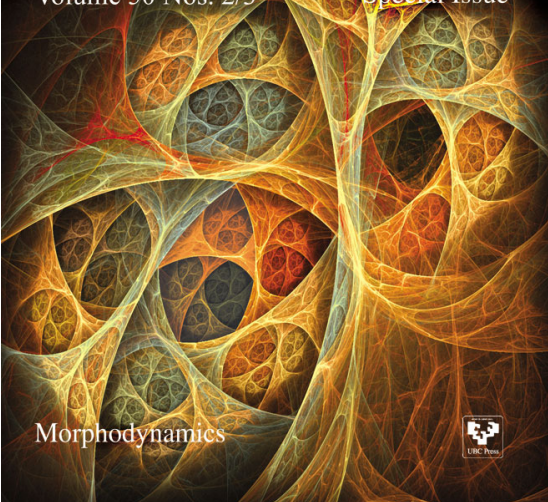

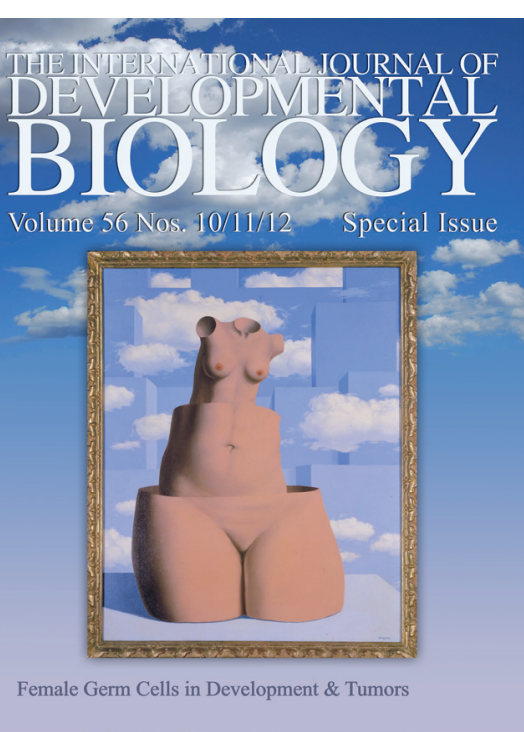
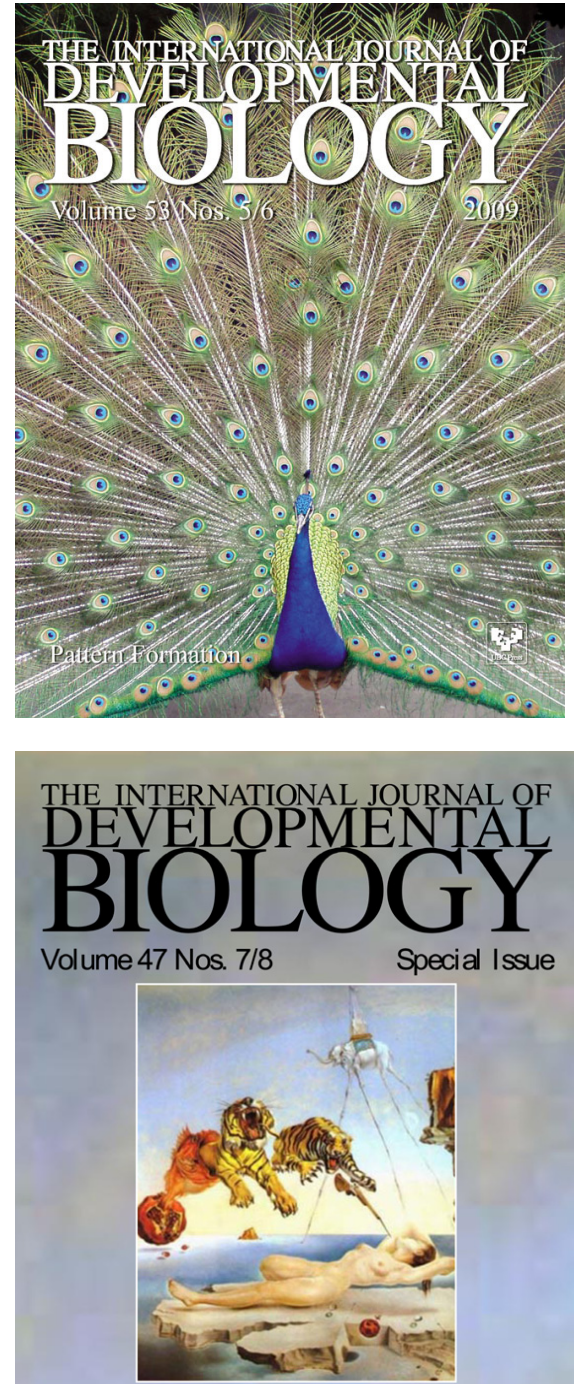

Evolution \& Development 